\title{
Rejection of a Manuscript and Career Resilience
}

\author{
Lee Demetrius Walker, University of North Texas
}

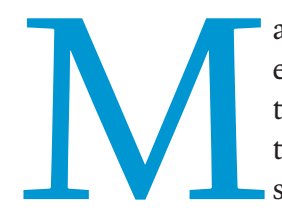
anuscript rejection is a form of failure that every academic experiences. It is a part of the academic job, and learning to cope with this rejection is a necessary part. Manuscript rejection is particularly impactful in the early-career stage. Day $(2011,706)$ argues that " $[\mathrm{n}] \mathrm{ew}$ entrants to academe must be mentored or carefully nurtured, or they may be overcome by the pains of rejections." This concern is particularly true for new assistant professors because their initial journal submissions are likely to be ideas that are extracted from their dissertations-documents to which they have invested several years of effort.

In this article, I use my personal experience with a single manuscript-for which it took me eight years to find a publishing home-to discuss aspects of overcoming the implications of manuscript rejection. I offer this to show the value of resilience in successfully publishing a paper in which a scholar's academic identity is highly connected.

This article is structured in the following manner. First, I discuss the relationship between academic identity and manuscript rejection through my own reflections. This discussion is guided by Day's $(2011,712)$ observation that many academics do not "fully appreciate the psychological dynamics of our need to belong, stigma and threats to social identity, and the social inclusion implications of manuscript rejection." Second, I introduce and describe the first submission of the manuscript of interest that meanders through the academicjournal-submission process. Third, I discuss the importance of acquiring social support in the aftermath of a manuscript rejection. Fourth, I describe my subsequent attempts to find a publishing home for the paper and my process of learning to use reviewers successfully. The final section discusses lessons that I learned from the process of publishing this manuscript.

\section{IDENTITY AND MANUSCRIPT REJECTION}

I first presented my paper entitled "The Distance Is All: Judicial Separation and Legitimacy in Latin America Presidential Democracies" at the 2005 Midwest Political Science Association Annual Meeting in Chicago. The paper introduced a deviation method to specify judicial legitimacy that should be useful cross nationally. I was invested in this paper because it was one of the ideas from my dissertation that I believed could be a contribution to the comparative judicial politics community. It was part of the identity that I had constructed for myself.
Day $(2011,707)$ posits that manuscript rejection can be viewed as a form of identity theft. If this is true, it is a particularly heinous crime in that the scholarly community that perpetrates it is unaware of both its thievery and its effects on a scholar. Day makes this point when she explains that the pressure to publish is both internal and external. Internally, Day $(2011,707)$ posits that "[p]ublishing satisfies our [academic's] need to belong to the social identity of successful scholars." Externally, Day $(2011,708)$ points out that the "research community expects its members to publish, and thus rejections are evidence that the person [who is rejected] 'can't cut it."'

The young scholar's identity is fractured from the start. You must establish yourself as an individual thinker who is capable of performing rigorous academic research while also connecting to a larger scholarly community that will judge your capacity to be a member of it. For me, I may have been luckier than most in establishing an identity that would be somewhat resilient to rejection. This resilience arises from the fact that I chose to do scholarship that is unconventional for an individual in my demographic group. I am an African American male, attended a small liberal arts college, and had entered a doctoral program as an older graduate student. Moreover, neither of my parents had completed high school. In turn, I had no expectation or illusion that I would easily complete my doctoral training and attain a faculty position at a Research-1 institution. In other words, I expected difficulty and, certainly, manuscript rejection would be part of this difficulty.

Nevertheless, I found the doctoral program at the University of Florida to be a wonderful and welcoming training ground. I was successful and lucky to attain a Research-1 job at the University of Kentucky. I did form an identity. I viewed myself as a comparativist, a comparative judicial scholar, and a Latin Americanist. Day $(2011,708)$ argues that "[s]ocial identities allow people to cognitively separate from the broader social environment and position themselves within it." This aspect of social-identity theory infers that new assistant professors (as I was in 2003) are likely to assume that their success in the scholarly community is linked to how well they craft their identity as a member of that group.

\section{THE FIRST SUBMISSION}

In January 2006, I submitted the paper to the Journal of Politics $(J O P)$; it was rejected. I received three reviews for the paper, which offered the following criticism: 
1) "After reading the paper a couple of times I am still a bit confused as to the logical and empirical linkages that the author tries to establish between the concepts of judicial separation, democratic development, and legitimacy. In part, I think this confusion comes from the lack of precise conceptual definitions of these terms."

2) "The manuscript reads like two papers. The first considers the link between judicial separation and democratic performance. The second addresses the link between judicial separation and specific support for judges. I believe that the author should make a choice."
From the discussion, we converged on the relationship between public support for the police and presidential candidates' use of police legitimacy to accentuate their support for law and order. This collaboration resulted in an article titled "Elections as Focusing Events: Attitudes toward the Police and the Government in Comparative Perspective" that was published in Law and Society Review (Walker and Waterman 2008).

Third, obsessing over the rejected manuscript will minimize the author's ability to produce other publishing projects. Obsessing over a rejected manuscript can lead to writer's block in the sense that young scholars may have difficulty responding

\section{The young scholar's identity is fractured from the start. You must establish yourself as an individual thinker who is capable of performing rigorous academic research while also connecting to a larger scholarly community that will judge your capacity to be a member of it.}

3) "This is an example of a novel paper with a novel and interesting theoretical purpose that is confusing and has too much going on in its current state, but the contribution of this paper is likely to be significant."

These reviews were disappointing but encouraging. They indicated that my paper tackled an important under-examined topic and could result in two publishing projects. I also received encouragement and advice from the former JOP editor, Bill Jacoby. He told me that "If people do not understand what you are trying to say, you need to find a way to say it better." I always remember this advice because it suggests an iterative process to the publication of research. Armed with this advice and the reviews, I began to think about my next steps.

\section{OVERCOMING SILENCE AND FINDING ALLIES}

The first step to successfully overcome a rejection is not to be silent about it. Day $(2011,705)$ points out that "[i]n silence, scholars have little ability to make critical social comparisons that could help them overcome rejection's negative effects." Not talking with others about the rejection has other negative implications. First, authors who have been rejected may individualize and internalize their rejection as failure. It is important that young scholars do not individualize manuscript rejection. Understanding that every scholar faces rejection reveals to young scholars that managing manuscript rejection is part of the duties of members of any scholarly community.

Second, authors who have been rejected can become isolated in attempting to correct the deficiencies of their rejected manuscript. If young scholars choose to isolate themselves after manuscript rejection, they will miss important opportunities to interact with other members of their scholarly community. These interactions can lead to collaborations beyond their current research project and to new publishing opportunities.

I had a chance to discuss my rejection with the then-chair of my department, Richard Waterman (University of Kentucky). Rick and I discussed areas in which our research overlapped. to reviewers' criticisms. It is not that young scholars are unable to produce research; it is more that they are confining their thoughts solely to the rejected manuscript.

\section{SUBSEQUENT SUBMISSIONS AND LEARNING TO USE REVIEWERS}

As mentioned previously, I was not silent about my manuscript rejection. I received advice to not hold onto the rejected manuscript but rather to get the revised version out for review as quickly as possible. For me, there were two primary questions that I needed to answer: (1) Should I attempt to aim for a different type of journal?; and (2) Should I restructure the manuscript as two (rather than one) article(s)?

There were several ways to approach the first question. I could choose to revise the paper for submission to another top-tier general journal, revise the paper for submission to a second-tier general journal, revise and submit the paper to a top-tier subfield journal, revise and submit the paper to a top-tier area-study journal, or revise and submit the paper to a third-tier journal where the acceptance rate would be much higher.

Deciding which type of journal to submit the revised paper to was important because it would dictate the focus of the revision. I opted to continue to try to publish in a top-tier general journal. This is because departments and the larger discipline place pressure on young faculty to publish in the top journals in their discipline. For example, until recently, the tenure standards in my current department (University of North Texas) had a provision that called for tenure candidates to have two publications in general-publishing venues.

The second question is related to how seriously to take the suggestions of reviewers. Because of the thoughtfulness of the reviews that I received, I sought to better explain my theoretical concerns, definitions of the concepts, and measurement of the judicial legitimacy. In my first revision, I decided to maintain the paper as a single coherent idea. After the reformulation, I submitted it to the American Journal of Political 
Science in 2006. I changed the title to "Judicial Separation and Legitimacy in Latin American Presidential Democracies." The paper was rejected again. In 2007, I submitted a further revised version to the British Journal of Political Science (BJPS). In this version, I attempted to make the paper more concise by focusing only on the countries of Costa Rica, El Salvador, and Nicaragua. I retitled the paper, "Judicial Separation amidst Declining Judicial Confidence: Evidence from Central America." After the BJPS rejection, I submitted the paper to Comparative (see also Shephard, Patzelt, and Wolfe 2011). The key to this type of intervention for young faculty is having mentors who are willing to share their stories about rejection. It is helpful for them to hear successful scholars share their experiences. I recall a conversation with Gary King (Harvard University) when I was on a postdoctoral fellowship at the Institute for Quantitative Social Science. I was speaking with Gary about one of my recent rejections, and he casually remarked that he had enough rejections to wallpaper his house. My reaction was,

\section{This normalization of rejection is also how young scholars begin to understand that rejection is a key ingredient to success.}

Political Studies; it was rejected again. The reviews from these submissions were useful but confirmatory that the complexity of my idea needed to be simplified.

From the initial reviews, the JOP reviewers suggested that I rework the paper into two papers: (1) one that emphasized the measurement of judicial legitimacy, and (2) and one that emphasized attitudes of citizens toward the democratic regime. The regime-type paper was published first and almost immediately. This paper was retitled as "Delegative Democratic Attitudes and Institutional Support in Central America"; it was published in Comparative Politics (Walker 2009). This paper established that individuals with delegative democratic attitudes evaluate institutions in a distinctive manner from liberal democrats and authoritarians. On the one hand, it seems that I should have immediately followed the reviewer's suggestion, and this conclusion may be correct. On the other hand, it may have taken me several iterations to write the paper well enough for publication.

Meanwhile, the measurement paper most exemplified my interest in comparative judicial politics. I continued to labor to have this paper accepted. The new title was "Building Support for the Democratic Judiciary: Explaining Mass Publics' Support for the Latin American Judiciary." In various forms, I submitted the paper to Political Research Quarterly, Journal of Latin American Studies, Journal of Law and Courts, and Journal of Politics in Latin America. In all of these iterations, I emphasized the area (i.e., Latin America) focus of the paper.

A few reviewers indicated that I needed more statistics in the paper. I personally thought the additional statistical method was unnecessary, and I had support for my approach in the literature on multilevel statistical models. Nonetheless, I decided it was necessary to comply with the suggestion. The title of the final iteration of the paper was "A Multilevel Explanation of Mass Support for the Judiciary." I submitted it to the Justice System Journal. After one revise-and-resubmit round, it was accepted (Walker 2016).

\section{LESSONS LEARNED FROM MANUSCRIPT REJECTION}

Day and Porter $(2017,12-13)$ make the useful suggestion that training in academic disciplines should include programs that have the "specified goal of normalizing failure"
"Wow, if someone as successful as Gary mentions rejection so casually, then it is a normal part of the process." This normalization of rejection is also how young scholars begin to understand that rejection is a key ingredient to success.

Finally, I want to highlight a few generalizations that I take from this discussion. First, developing and internalizing an academic identity is important. I do not mean that this identity is all-consuming because we all have a life beyond academia. However, inside of the discipline, it is important to start with a clear picture of how you view yourself in your discipline and subfield. Some of the best advice I received was from my adviser, Leslie Anderson (University of Florida). She told me that you do not want people to confuse who you are as a scholar. I interpreted this to mean that I should be true to myself as a scholar and this will guide me through my career. The internalization of identity is individualistic and aligns with that portion of the academic career that fosters individualism.

Second, it is important to find mentors in your home department and in your subfield, which is not always easy. In some departments, the new faculty member may be the only person who does what she does. In this case, it is beneficial to find someone in your department with whom you can discuss your research. Also, it is important to maintain a relationship with faculty from your PhD-granting institution. Your committee members are valuable resources. Moreover, you should find mentors outside of your university who may or may not work in the same subfield. Although it is helpful to have mentors in your subfield, rejection is universal.

Third, mentors can help you only if you are open and honest about manuscript rejection. The positive side of being open is that it leads to discussion with mentors, who have had their own experiences with rejection.

Fourth, it is important to listen to reviewers. I know that we have all been frustrated with comments from "bad" reviews and reviewers. Nonetheless, there is great value in good reviews. As my experience illustrates, several valuable suggestions came from reviewers, and those suggestions helped me to eventually publish two articles.

Fifth, although my intent in this article is to offer insight on the value of resilience in the publishing process, this discussion 
connects with Kammeyer-Mueller, Judge, and Scott's (2009) summary on coping with manuscript rejection. They posit coping with manuscript rejection as the following fourstep process: (1) receive and craft an initial response to the rejection; (2) share your rejection with your social network; (3) reframe your rejection response; and (4) formulate a problem-solving strategy to move past the rejection.

\section{REFEREN CES}

Day, Nancy Evelyn. 2011. "The Silent Majority: Manuscript Rejection and Its Impact on Scholars.” Academy of Management Learning E Education 10 (4): 704-18.

Day, Nancy E., and Tracy H. Porter. 2017. "Lacerations of the Soul: Rejections-Sensitive Business School Faculty and Perceived
Publication Performance." Journal of Leadership \& Organizational Studies 25 (1): 101-15

Kammeyer-Mueller, John D., Timothy A. Judge, and Brent A. Scott. 2009 "The Role of Core Self-Evaluations in the Coping Process." Journal of Applied Psychology 94 (1): 177-95.

Shephard, Dean A., Holger Patzelt, and Marcus Wolfe. 2011. "Moving Forward from Project Failure: Negative Emotions, Affective Commitment, and Learning from the Experience." Academy of Management Journal 54 (6): 1229-59.

Walker, Lee Demetrius. 2009. "Delegative Democratic Attitudes and Institutional Support in Central America." Comparative Politics 44 (1): 83-101.

Walker, Lee Demetrius. 2016. "A Multilevel Explanation of Mass Support for the Judiciary." Justice System Journal 32 (3): 194-210.

Walker, Lee Demetrius, and Richard W. Waterman. 2008. "Elections as Focusing Events: Attitudes toward the Police and the Government in Comparative Perspective." Law \& Society Review 42 (2): 337-66. 